\title{
Response to commentary 'towards more meaningful scenarios of biodiversity responses to land-use change in Central Asia
}

\author{
Sarahi Nunez ${ }^{1}$ (D) $\cdot$ Rob Alkemade $^{1,2} \cdot$ Kasper Kok $^{1} \cdot$ Rik Leemans $^{1}$
}

Received: 25 May 2020 / Accepted: 26 May 2020 / Published online: 26 June 2020

(C) The Author(s) 2020

\begin{abstract}
With this letter, we respond to the commentary by Kamp et al. on our paper (Nunez et al. in Reg Environ Chang 20:39, 2020) that reports on potential biodiversity change in Central Asian grasslands using climate and land-use change scenarios. In their commentary, Kamp et al. criticize data and methods employed and discuss several shortfalls of our approach. In this response, we argue that in our paper projections of future biodiversity already acknowledge the issues indicated by Kamp et al. We elaborate on the reasons why. We maintain our main finding that, based on a number of contrasting scenarios (shared socioeconomic pathways and representative concentration pathways combinations), biodiversity in grasslands in Central Asia will potentially decline under each scenario. We conclude that while our data and methods conservatively estimate potential biodiversity changes in the Central Asian grasslands, they could be enriched with more elements. The results, however, are likely to confirm the vulnerability of these grasslands and the possible decline in their biodiversity.
\end{abstract}

Keywords Biodiversity change $\cdot$ Land-use scenarios $\cdot$ Grazing intensification $\cdot$ Grasslands

Response to commentary

We thank Kamp et al. for their very insightful comments and feedback on our article and particularly for acknowledging our effort to project biodiversity responses across Central Asia.

As mentioned in the original paper, our results translate relevant information of socioeconomic and climate change drivers and stress the potential vulnerability of this region to increasing land-use intensity and climate change. We have shown that the elements included in the shared socioeconomic pathways (SSPs) developed for Central Asia and representative concentration pathways (RCPs) and their underlying assumptions drive the larger changes in this grassland system. At the same time, we stress that more research is urgently

This article is a respond to Commentary https://doi.org/10.1007/s10113020-01666-x.

Sarahi Nunez

sarahi.nunezramos@wur.nl

1 Environmental Systems Analysis Group, Wageningen University and Research, PO Box 47, 6700, AA Wageningen, The Netherlands

2 PBL-Netherlands Environmental Assessment Agency, PO Box 30314, 2500, GH The Hague, The Netherlands needed to translate our findings into better management strategies for Central Asia's grasslands. Observations remain scarce, as available (global) assessments poorly represent this extensive grassland area. We fully agree with Kamp et al. in that future scenarios of biodiversity responses to environmental change in Central Asia will benefit from the use of regional, thematically and spatially detailed data on livestock and grassland/cropland distribution. We here address a response to four shortfalls discussed by Kamp et al.

First, the use of an inadequate measure of biodiversity intactness'. The Mean Species Abundance (MSA) is a widely used metric to indicate local biodiversity intactness or naturalness. In other words, MSA describes biodiversity changes with reference to the original state of ecosystems. This metric is quantified based on data that describe changes in community composition in relation to particular pressures, land use and climate change (Alkemade et al. 2009; Schipper et al. 2019). It has been parameterized in the GLOBIO model, a global model of biodiversity intactness (Alkemade et al. 2009). Our study aimed to estimate potential change of biodiversity in the Central Asian grasslands as a result of the impacts of socioeconomic trends and the consequent projections of land use and climate change. The MSA metric has indeed been parameterized using data from all regions across the world. Analyses, however, showed no significant difference 
of impacts on MSA between the different world regions, indicating similar responses of biodiversity across the world. We thus decided that the MSA metric was appropriate to estimate biodiversity loss in Central Asia. In addition, the parameterization of grazing intensity (Alkemade et al. 2013) included observations of species abundances from grazing land compared to surrounding natural grasslands (e.g. Wang et al. 2002) and from the study area (Sánchez-Zapata et al. 2003). While the study by Sánchez-Zapata et al. (2003) in eastern Kazakhstan does not indicate the degradation state of the surveyed habitats, it does clearly indicate four different habitat types with different levels of human intervention in their land use (and an indication of population pressure). The study concludes that transformations in steppe habitats determine strong variations in species composition, in this case of the different raptor communities. This is precisely what the parameterization in the GLOBIO model needs, the impact of a specific pressure (i.e. transformation) on species. The climate-change impact, derived from Nunez et al. (2019), could not directly include data from Central Asia. In this case, an extended literature search identified publications that assessed impacts of climate change on species abundance and distribution in similar grasslands (Zhang et al. 2013; Su et al. 2018). From these papers, we concluded that climate change can lead to a potential range contraction in the future distribution of species in Central Asian grasslands. In short, we maintain that we have employed an appropriate, widely used and widely cited metric that can be used to assess potential biodiversity loss in Central Asia.

Second, a failure to acknowledge the large spatial variation in land-use trends across the five considered Central Asian countries. Obviously, the Central Asian republics have all moved in separate directions after the collapse of the Soviet Union, and this also had consequences for land use change processes. These deserve to be studied, and we are looking forward to see country-specific analyses on future land use change. In our study, we aimed at including overall land-use trends in Central Asia, depending largely on existing, consistent data, which was mostly global. We combined different datasets, scenario and model assumptions, which are widely used by the scientific community. Importantly, the socioeconomic scenarios were developed during two stakeholder workshops that brought together multiple experts from all five republics. We openly invited stakeholders to be country-specific, where needed. Resulting scenarios mostly focused on changes in the region as a whole. But most importantly, we indicated in our original paper, 'when studying the 'meso scale', it is always challenging to strike a balance between local expert knowledge, detailed data, and process-based information, and area-covering data and generally applicable rules consistent with the model architecture'. In our paper, we took a predominantly top-down approach, based on global data and Central Asian trends. As a result, when applying our biodiversity model, we faced difficulties to include all regionally important processes, as rightly stated by Kamp et al. Although we acknowledge that a top-down approach has disadvantages, we disagree with the general message from Kamp et al. that they should be abandoned completely and replaced by bottom-up, local studies. There is nothing wrong with a bottom-up approach, but including more diversity and variation will not necessarily lead to improved region-wide insights other than that everything is diverse. Moreover, while we acknowledge that there are spatial differences in land-use trends across the region, our results do indicate potential biodiversity loss, particularly relative to other regions in the world. We certainly maintain that future studies will benefit from using regional spatial data on livestock distribution and land-use patterns, also when derived from widely used global datasets.

Third, the fact that we assume a strictly linear, negative relationship between livestock grazing intensity and the abundance of animals and plants. As indicated before, we used the MSA metric as an indication of biodiversity change. MSA only looks at the abundance of original local species. Increases in individual species abundance from reference to impacted situations are truncated to avoid the indicator being inflated by opportunistic or generalist species that benefit from habitat disturbance (Schipper et al. 2019). As correctly stated by Kamp et al., relationships between grazing intensity and species abundance are often hump-shaped, and the grasslands of Central Asia are no exception. Yet, the increase of the number of species might be caused by the appearance of non-native species, or at least species that were not originally present. In our original paper, we discuss that a moderate intensification of free-ranging grazing systems could be beneficial to restore near-natural steppe communities across most of the study area (Kamp et al. 2009; Dara et al. 2019). These changes are not reflected in the MSA metric, for the previously mentioned reason. In some cases, for example if land use intensification decreases, the impacts on biodiversity could be reflected as an increase in the MSA. The potential increases of certain (groups of) species are not reflected in the MSA metric. This is consistent with literature that shows that, although increases are observed with intensification, there is consensus that overall habitats are lost, which negatively impacts biodiversity (Newbold et al. 2015). The strictly linear, negative relationship needs to be interpreted accordingly. In short, we maintain that the negative relationship is useful in interpreting changes in biodiversity. We also acknowledge that other metrics should be applied and compared in order to improve understanding of the link between land use and biodiversity.

Fourth, the extrapolation of grazing-related biodiversity responses into areas of cropland. The employed scenarios used Global Land Cover (GLC2000) with a spatial resolution of $0.0089^{\circ} \times 0.0089^{\circ}$ from the Joint Research Centre (2003) as input to indicate different land-use patterns in the region. This 
importantly allowed to maintain consistency with other input data (Alkemade et al. 2013; Petz et al. 2014). There is a scientific debate about the value of different global land cover and land use maps, all of which have their (dis)advantages (Alexander et al. 2017). For example, the GLC2000 dataset presents the category 'mosaic' with mixed cropland and shrub/grass cover. In our study, we decided to aggregate the mixed categories such as mosaic and shrub, herbaceous covers (i.e. grasslands), given that the percentage coverage of grassland in mosaic classes was higher than cropland. Under this premise, crop production on arable land was to some extent part of the analysis. Furthermore, in our study, we indeed considered only livestock grazing as land use. We agree that future work should aim to include changes in other land classes, particularly those feedlot-based systems that are coupled with intensive hay and crop production.

\section{Conclusion}

We maintain our main finding that, based on a number of contrasting scenarios (SSP-RCP combinations), biodiversity in grasslands in Central Asia will potentially decline under each scenario. In our original paper, we took a predominantly top-down approach with the overall aim to study changes in land use, climate, and potential biodiversity as a result of socioeconomic trends to improve understanding of Central Asian biodiversity in the global context. Relative to the global context, we enriched and detailed our understanding of the region. We understand that from a regional or national perspective this study could be enriched with a range of elements, including for instance restoration of abandoned land, fire occurrence, or species-specific responses. However, we argue that the results of our modelling exercise indicate potential for biodiversity loss, certainly relative to other regions in the world. With this, we fill important knowledge gaps in global assessments. Other (regional) studies with GLOBIO have indicated the importance of such applications (e.g. Trisurat et al. 2010; Trisurat et al. 2014). The four 'shortfalls' that Kamp et al. mentioned are in fact not methodological flaws, but direct consequences of employing a top-down approach. We regret that Kamp et al. regard this internationally accepted approach as 'inadequate' for the topic of grasslands in Central Asia, but given the underlying goal, we disagree.

Having said that, we do strongly support the suggestion by Kamp et al. that future work on scenarios of biodiversity response to regional environmental change in Central Asia should include and build on regional and national data and knowledge that examines the relationship between land-use intensity and species richness and abundance. As these studies are currently very limited, we urge the importance of primary research, particularly in the Central Asian region.

Open Access This article is licensed under a Creative Commons Attribution 4.0 International License, which permits use, sharing, adaptation, distribution and reproduction in any medium or format, as long as you give appropriate credit to the original author(s) and the source, provide a link to the Creative Commons licence, and indicate if changes were made. The images or other third party material in this article are included in the article's Creative Commons licence, unless indicated otherwise in a credit line to the material. If material is not included in the article's Creative Commons licence and your intended use is not permitted by statutory regulation or exceeds the permitted use, you will need to obtain permission directly from the copyright holder. To view a copy of this licence, visit http://creativecommons.org/licenses/by/4.0/.

\section{References}

Alexander P, Prestele R, Verburg PH, Arneth A, Baranzelli C, Batista e Silva F, Brown C, Butler A, Calvin K, Dendoncker N, Doelman JC, Dunford R, Engström K, Eitelberg D, Fujimori S, Harrison PA, Hasegawa T, Havlik P, Holzhauer S, Humpenöder F, Jacobs-Crisioni C, Jain AK, Krisztin T, Kyle P, Lavalle C, Lenton T, Liu J, Meiyappan P, Popp A, Powell T, Sands RD, Schaldach R, Stehfest E, Steinbuks J, Tabeau A, van Meijl H, Wise MA, MDA R (2017) Assessing uncertainties in land cover projections. Glob Chang Biol 23:767-781. https://doi.org/10. $1111 / \mathrm{gcb} .13447$

Alkemade R, Reid RS, van den Berg M, de Leeuw J, Jeuken M (2013) Assessing the impacts of livestock production on biodiversity in rangeland ecosystems. Proc Natl Acad Sci 110:20900-20905. https://doi.org/10.1073/pnas.1011013108

Alkemade R, van Oorschot M, Miles L, Nellemann C, Bakkenes M, ten Brink B (2009) GLOBIO3: a framework to investigate options for reducing global terrestrial biodiversity loss. Ecosystems 12:374 390. https://doi.org/10.1007/s10021-009-9229-5

Newbold T, Hudson LN, Hill SLL, Contu S, Lysenko I, Senior RA, Borger L, Bennett DJ, Choimes A, Collen B, Day J, De Palma A, Diaz S, Echeverria-Londono S, Edgar MJ, Feldman A, Garon M, Harrison MLK, Alhusseini T, Ingram DJ, Itescu Y, Kattge J, Kemp V, Kirkpatrick L, Kleyer M, Correia DLP, Martin CD, Meiri S, Novosolov M, Pan Y, Phillips HRP, Purves DW, Robinson A, Simpson J, Tuck SL, Weiher E, White HJ, Ewers RM, Mace GM, Scharlemann JPW, Purvis A (2015) Global effects of land use on local terrestrial biodiversity. Nature 520:45-50. https://doi.org/10. 1038/nature14324

Nunez S, Alkemade R, Kok K, Leemans R (2020) Potential biodiversity change in Central Asian grasslands: scenarios for the impact of climate and land-use change. Reg Environ Chang 20:39. https:// doi.org/10.1007/s10113-020-01619-4

Nunez S, Arets E, Alkemade R, Verwer C, Leemans R (2019) Assessing the impacts of climate change on biodiversity: is below $2{ }^{\circ} \mathrm{C}$ enough? Clim Chang 154:351-365. https://doi.org/10.1007/ s10584-019-02420-x

Petz K, Alkemade R, Bakkenes M, Schulp CJE, van der Velde M, Leemans R (2014) Mapping and modelling trade-offs and synergies between grazing intensity and ecosystem services in rangelands using global-scale datasets and models. Glob Environ Chang 29: 223-234. https://doi.org/10.1016/j.gloenvcha.2014.08.007 
Sánchez-Zapata JA, Carrete M, Gravilov A, Sklyarenko S, Ceballos O, Donázar JA, Hiraldo F (2003) Land use changes and raptor conservation in steppe habitats of eastern Kazakhstan. Biol Conserv 111: 71-77. https://doi.org/10.1016/S0006-3207(02)00251-3

Schipper AM, Hilbers JP, Meijer JR, Antão LH, Benítez-López A, de Jonge MMJ, Leemans LH, Scheper E, Alkemade R, Doelman JC, Mylius S, Stehfest E, van Vuuren DP, van Zeist W-J, Huijbregts MAJ (2019) Projecting terrestrial biodiversity intactness with GLOBIO 4. Glob Chang Biol 26:760-771. https://doi.org/10. $1111 / \mathrm{gcb} .14848$

Su J, Aryal A, Hegab IM, Shrestha UB, Coogan SCP, Sathyakumar S, Dalannast M, Dou Z, Suo Y, Dabu X, Fu H, Wu L, Ji W (2018) Decreasing brown bear (Ursus arctos) habitat due to climate change in Central Asia and the Asian Highlands. Ecology and Evolution 8: 11887-11899. https://doi.org/10.1002/ece3.4645

Trisurat Y, Alkemade R, Verburg PH (2010) Projecting land-use change and its consequences for biodiversity in Northern
Thailand. Environ Manag 45:626-639. https://doi.org/10.1007/ s00267-010-9438-x

Trisurat Y, Kanchanasaka B, Kreft H (2014) Assessing potential effects of land use and climate change on mammal distributions in northern Thailand. Wildl Res 41:522-536. https://doi.org/10.1071/ wr14171

Wang Y, Shiyomi M, Tsuiki M, Tsutsumi M, Yu X, Yi R (2002) Spatial heterogeneity of vegetation under different grazing intensities in the Northwest Heilongjiang Steppe of China. Agric, Ecosyst Environ 90:217-229. https://doi.org/10.1016/S0167-8809(01)00217-1

Zhang H-X, Zhang M-L, Sanderson SC (2013) Retreating or standing: responses of forest species and steppe species to climate change in arid eastern Central Asia. PLoS One 8. https://doi.org/10.1371/ journal.pone.0061954

Publisher's note Springer Nature remains neutral with regard to jurisdictional claims in published maps and institutional affiliations. 